\title{
Keratoacanthomas and Squamous Cell Carcinomas on Tattoos: A Review of 42 Cases
}

\author{
Nicolas Kluger ${ }^{a, b} \quad$ Bernard Cribier ${ }^{c}$ \\ a "Tattoo" Consultation, Department of Dermatology, Bichat-Claude Bernard Hospital, Assistance Publique-Hôpitaux \\ de Paris, Paris, France; ${ }^{b}$ Department of Dermatology, Allergology and Venereology, Skin and Allergy Hospital, \\ Helsinki University Hospital, Helsinki, Finland; ' $C$ Clinique Dermatologique, Hôpitaux Universitaires et Université de \\ Strasbourg, Strasbourg, France
}

\section{Keywords}

Keratoacanthoma - Laser removal · Red ink - Squamous cell carcinoma $\cdot$ Sun exposure $\cdot$ Tattooing

\section{Introduction}

The occurrence of cutaneous tumors on permanent tattoos has been reported since the fifties. Melanomas (MMs), basal cell carcinomas (BCCs), squamous cell carcinomas (SCCs), and keratoacanthoma-type lesions (KAs) have been reported [1]. The literature failed thus far to provide robust argument supporting a non-fortuitous association for MMs and BBCs [2]. The lack of multiple lesions within one tattoo and the overall low number of cases plead for a background noise rather than causality [3]. A malignant or premalignant lesion can also be inadvertently tattooed over, and its evolution masked by the drawing. On the other hand, reports of rapidly arising, isolated or multiple KAs and SCCs on the red part of tattoos tend to suggest a non-fortuitous link with the procedure [4]. We herein review all case reports of KAs and SCCs that occurred on tattoos thus far and analyze the clinical features of the patients with such complications.

\section{Material and Methods}

We performed a review of the existing literature on the database MEDLINE (1946-2020) using the following keywords "tattoo or tattoos or tattooing" AND "squamous cell carcinoma" or "keratoacanthoma" or "keratoacanthomas" with no restriction until 2020. All articles reporting on $\geq 1$ case(s) of confirmed KAs or SCCs were included. We excluded cases of pseudo-epitheliomatous hyperplasia. The first author has already published an exhaustive review of 31 patients in 2017 in French [4]. The present review is an update with the addition of the most recent cases [5-13] as well as two cases diagnosed at the "Tattoo consultation" in Bichat - Claude Bernard Hospital, in Paris [14, 15].

\section{Results}

To the best of our knowledge, we found 42 case reports or series of isolated or multiple KAs and SCCs on tattoos. The main characteristics are summarized in Table 1 . Briefly, patients are usually middle-aged (median 52 years, range 24-79) with a history of skin cancer in $12 \%$. Lesions usually develop rapidly with a median delay of 1 month after tattooing or after laser removal. Exceptional cases have been described in old tattoos with rather long delay of onset (9 and 10 years). In 2 karger@karger.com

(c) 2020 S. Karger AG, Basel

www.karger.com/drm

Karger ${ }^{\prime}=$
Nicolas Kluger

Department of Dermatology

Skin and Allergy Hospital, Helsinki University Hospital

Meilahdentie 2, PO Box 160 FI-00029 HUS (Finland)

nicolas.kluger@hus.fi 


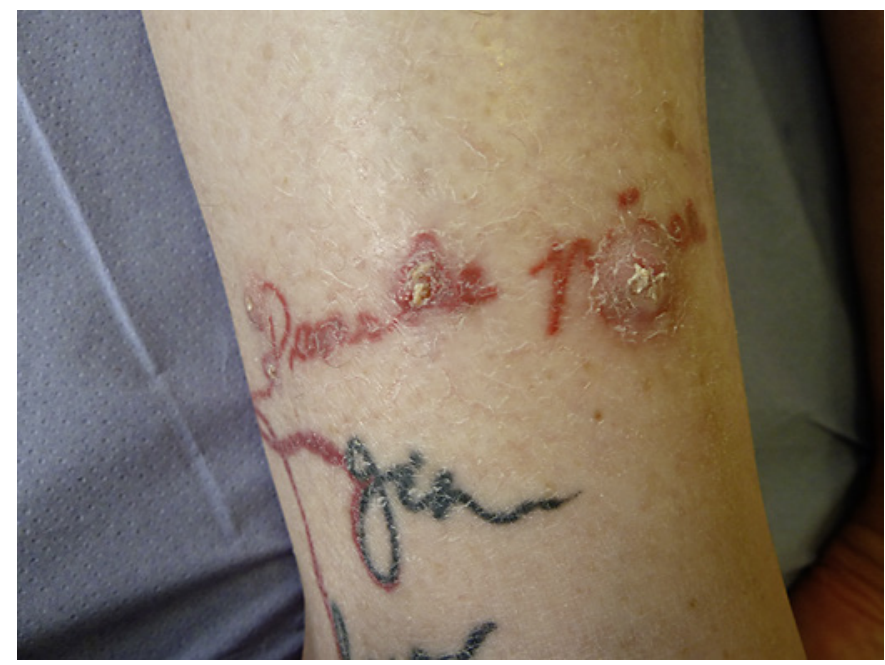

Fig. 1. Eruptive KAs on a red tattoo of the ankle in a 57-year-old woman.

other cases, the tattoos were very old tattoos (21 and $>50$ years), but the articles failed to provide delay of onset [4]. Multiple ( $>1)$ lesions are observed in $40.5 \%$ of the cases. Red was the most commonly affected color (almost in $75 \%$ of the cases). Tattoos were either located on the lower (53.6\%) or upper limbs (40\%) (Fig. 1). Sun exposure after tattooing could be an additional triggering factor as illustrated by cases with lesions restricted only to sun-exposed areas [14]. However, such information was overlooked in most of the reports. Two patients $(<5 \%)$ developed KAs after laser removal sessions $[8,9]$, and 2 others had KAs after a tattoo was touched-up $[7,10]$.

\section{Discussion}

Our review confirms a specific pattern of KA affecting mostly red tattoos on the extremities of middleaged individuals. Apart from getting a new tattoo, other triggering factors include an old tattoo touched-up, laser removal, or sun exposure after tattooing [4]. KA can be associated with immunosuppression, ultra-violet (UV) or X-rays, drug treatments, foreign bodies, and various trauma (surgery, peels, abrasions, cryotherapy, and photodynamic therapy) [16]. Tattoo-associated $\mathrm{KA}$ is most likely of multifactorial origin, combining needle trauma, local inflammation, external factors such UV exposure, and a possible predisposition related to either skin (photo)aging or genetic background
Table 1. Characteristics of 42 cases of tattoo-associated KAs and SCCs

\begin{tabular}{ll} 
Male gender, $\%$ & $23(59.0)$ \\
Male:female sex ratio & 1.4 \\
Median age, years & 52 \\
Mean age (SD), years & $50.2(12.3)$ \\
Past history of skin cancer $(n=25)$ & \\
$\quad$ Yes* & $3(12.0)$ \\
$\quad$ No & $22(88.0)$ \\
$\quad$ Actinic keratoses & $3(12.0)$ \\
Delay at onset after tattooing, months & \\
$\quad$ Range & Immediately - $120^{* *}$ \\
$\quad$ Median & 1 \\
Multiple lesions of KA & $17(40.5)$ \\
Color (out of 43 tattoos) & \\
$\quad$ Red & $32(74.4)$ \\
$\quad$ Black & $3(7.0)$ \\
$\quad$ Multicolored & $7(16.3)$ \\
$\quad$ NA & $1(2.3)$ \\
Localization (out of 41 tattoos) & \\
$\quad$ Upper limbs & $16(40)$ \\
Lower limbs & $21(53.6)$ \\
Trunk & $1(2.4)$ \\
Face (lips) & $2(4.8)$ \\
Laser removal prior to onset & $2(4.8)$ \\
Old tattoo touched-up prior to onset & $2(4.8)$ \\
\hline
\end{tabular}

Values are $\mathrm{n}(\%)$, unless otherwise indicated. NA, not available; SD, standard deviation. * One patient had two BCCs, 1 patient a melanoma in situ of the scalp, multiple nonmelanoma skin cancers, and non-Hodgkin lymphoma. ** In 2 cases, tattoos were 21 and $>50$ years old, but no delay of onset was available.

(Fig. 2). Besides, the frequency of occurrence on red areas points out toward a specific compound or a byproduct. Azo pigments exposed to sunlight or laser can be photodegraded into a variety of products, some of which are toxic or even carcinogenic [17]. In a mouse model, Lerche et al. [18] showed that red ink containing 2 -anisidine could act as a cocarcinogen with UV radiations in the long term. We recently identified the same red azo pigment (Pigment Red 170, P.R. 170) in 3 different cases of KA [15]. In a recent study of the US market of tattoo inks, the most used red pigments are by order of frequency P.R. 210, P.R.101, P.R. 170, and P.R.122 [19]. P.R. 170 is not the most prevailing pigment found in skin biopsies from chronic red allergic reactions, but it is still found in $12 \%$ of the cases [20]. In our experience, we had 1 patient with a lichenoid reaction to red associated with KA, but we failed to find similar cases in our review. To date, allergic reaction does not appear to be a risk factor for KA. 


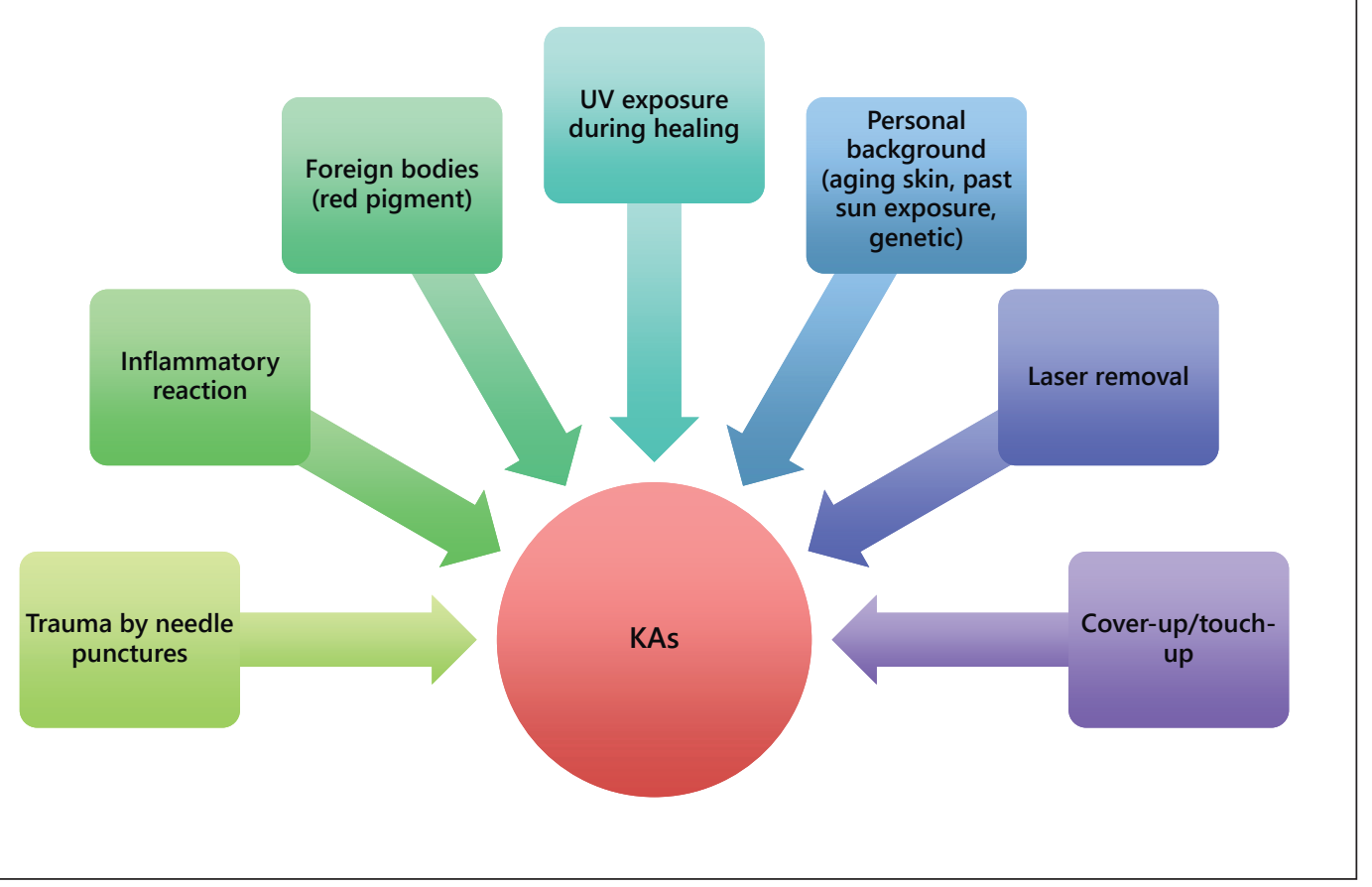

Fig. 2. Factors involved in the pathogenesis of tattoo-induced KAs.

Our preliminary results with P.R.170 need to be confirmed by the analyses of larger samples.

However, red is not the only color involved, exceptional cases on green [13] or black [4] have been reported for instance, so other pigments could be involved.

\section{Key Message}

Keratoacanthoma-type lesions in tattoos are primarily found in red and might be related to PR170 and needle trauma.

\section{Conflict of Interest Statement}

The authors have no conflicts of interest to declare.

\section{References}

1 Kluger N, Koljonen V. Tattoos, inks, and cancer. Lancet Oncol. 2012 Apr;13(4):e161-8.

2 Lerche CM, Sepehri M, Serup J, Poulsen T, Wulf HC. Black tattoos protect against UVRinduced skin cancer in mice. Photodermatol Photoimmunol Photomed. 2015 Sep;31(5): 261-8.

3 Cherkaoui El Baraka F, Kluger N, Ollivier I, Bourgoin R, Grossin M, Zeboulon C, et al. [Melanoma within tattoos: two cases and a systematic literature review]. Ann Dermatol Venereol. 2020 Apr;147(4):285-92.

4 Kluger N, Douvin D, Dupuis-Fourdan F, Doumecq-Lacoste JM, Descamps V. [Keratoacanthomas on recent tattoos: two cases]. Ann Dermatol Venereol. 2017 Dec;144(12): 776-83.

5 Maxim E, Higgins H, D'Souza L. A case of multiple squamous cell carcinomas arising from red tattoo pigment. Int J Womens Dermatol. 2017 Aug;3(4):228-30.
6 Shrout M, DeCoster R, Wermeling R, Vasconez HC. Risk Factors for Squamous Cell Carcinoma: A Case for Red Pigment in Tattoos. Am Surg. 2019 Feb;85(2):e77-8.

7 Milam EC, Leger MC, McClain SA, Brustein DM. Concurrent keratoacanthomas and nonsarcoidal granulomatous reactions in new and preexisting tattoos. Cutis. 2019 Feb; 103(2):E39-42.

8 Swigost AJ, Peltola J, Jacobson-Dunlop E, Goldfarb N. Tattoo-related squamous proliferations: a spectrum of reactive hyperplasia. Clin Exp Dermatol. 2018 Aug;43(6):728-32.

9 Hoss E, Kollipara R, Goldman MP, Tompkins SD. Eruptive Keratoacanthomas in a Red Tattoo After Treatment With a 532-nm Picosecond Laser. Dermatol Surg. 2020 Jul;46(7): 973-74.
10 Giberson M, Rogachefsky A, Lortie C. Finding Chemo for Nemo: Recurrent Eruptive Keratoacanthomas in a Tattoo. Dermatol Surg. 2019 Oct;Publish Ahead of Print: https://doi. org/10.1097/DSS.0000000000002227.

11 Queen D, Richards LE, Bordone L, Bickers DR, Husain S, Lewin JM. Multiple keratoacanthomas arising within red tattoo pigment. Cutis. 2019 Oct;104(4):E15-7.

12 Donnarumma M, Scalvenzi M, Fabbrocini G, Ferrillo M, Peduto T. Keratoacanthoma occurring in a recent skin tattoo and self-involuted after a punch biopsy. G Ital Dermatol Venereol. 2019 Sep. https://doi.org/10.23736/ S0392-0488.19.06407-1.

13 Boyd AS. Multiple keratoacanthomas arising in a new tattoo. Int J Dermatol. 2019 Jul. https://doi.org/10.1111/ijd.14606. 
14 Kluger N, Descamps V. Usefulness of a specialized «tattoo» consultation in a tertiary care hospital: a one-year experience. J Eur Acad Dermatol Venereol. 2019 Apr;33(4):e182-3.

15 Colboc H, Bazin D, Moguelet P, Reguer S, Amode R, Jouanneau C, et al. Chemical composition and distribution of tattoo inks within tattoo-associated keratoacanthoma. J Eur Acad Dermatol Venereol. 2020 Jul; 34(7):e313-15.
16 Kwiek B, Schwartz RA. Keratoacanthoma (KA): an update and review. J Am Acad Dermatol. 2016 Jun;74(6):1220-33.

17 Hauri U, Hohl C. Photostability and breakdown products of pigments currently used in tattoo inks. Curr Probl Dermatol. 2015;48: 164-9.

18 Lerche CM, Heerfordt IM, Serup J, Poulsen T, Wulf HC. Red tattoos, ultraviolet radiation and skin cancer in mice. Exp Dermatol. 2017 Nov;26(11):1091-6.
19 Liszewski W, Warshaw EM. Pigments in American tattoo inks and their propensity to elicit allergic contact dermatitis. J Am Acad Dermatol. 2019 Aug;81(2):379-85.

20 Serup J, Hutton Carlsen K, Dommershausen N, Sepehri M, Hesse B, Seim C, et al. Identification of pigments related to allergic tattoo reactions in 104 human skin biopsies. Contact Dermat. 2020 Feb;82(2):73-82. 